\title{
The Journey of Specimens: From the Operating Table to the Microscope
}

\author{
Ahmad Altaleb
}

\section{Objective}

- Understand the "big picture" of the basic steps carried out at the pathology laboratory in order to obtain glass slides, by illustrating the specimen's route all the way from the operation room to the pathologist's microscope.

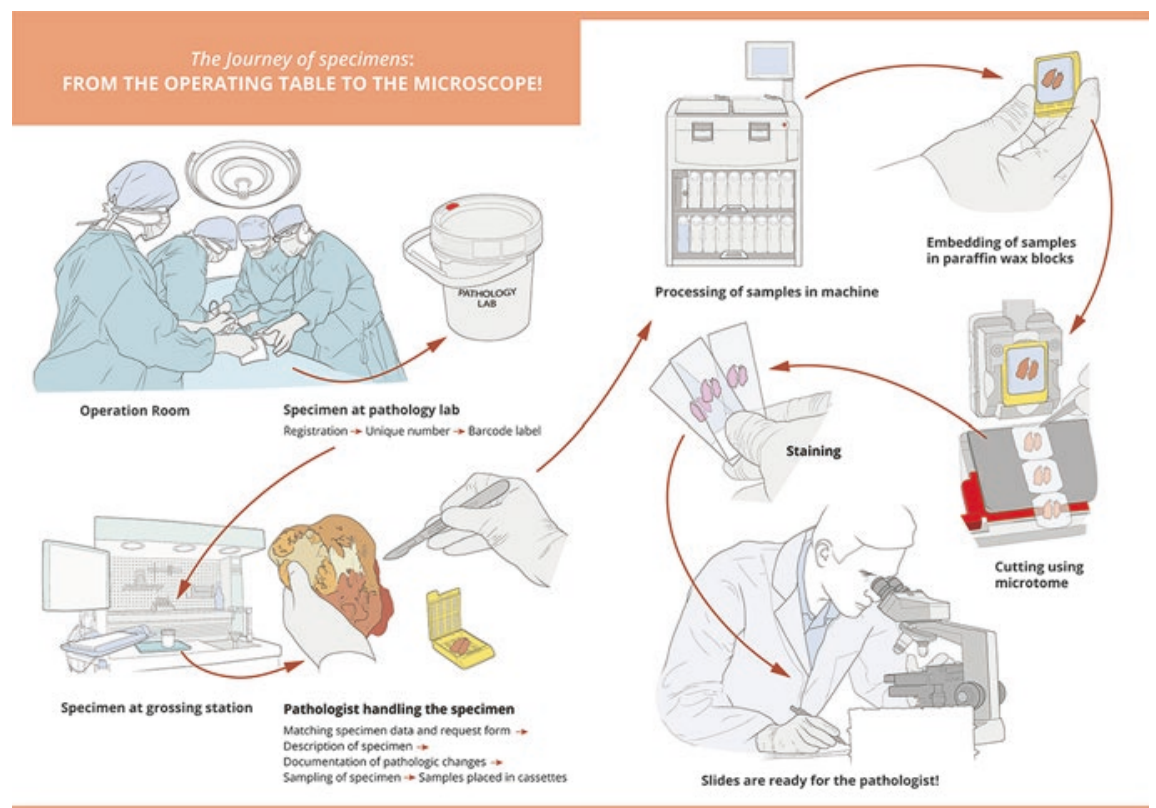

A. Altaleb (四)

Histopathology Department, Mubarak Alkabeer Hospital, Jabriya, Kuwait

(C) The Editor(s) (if applicable) and The Author(s), under exclusive license to Springer Nature Switzerland AG 2021

A. Altaleb (ed.), Surgical Pathology,

https://doi.org/10.1007/978-3-030-53690-9_6 